da Interculturalidade à Tecnologia

\title{
Lugares da memória na obra de Ayrson Heráclito
}

Marcelo Rafael de Carvalho é Mestrando pelo PPG Design da Universidade Anhembi Morumbi. Bolsista Capes Prosup/UAM/Bolsa. Possui graduação em Comunicação Social pela Universidade Mackenzie. Atuou como supervisor do serviço educativo do MAB (Museu de Arte Brasileira), assistente de coordenação do educativo do Instituto Cultural Itaú e coordenador da ação educativa da $26^{\circ}$ Bienal de São Paulo. <marcelorafac@gmail.com> ORCID: 0000-0001-5134-5963
Resumo 0 presente artigo tem como objetivo refletir sobre a videoinstalação Os Sacudimentos (2015), composta por dois vídeos denominados 0 Sacudimento da Casa da Torre (8'32') e O Sacudimento da Maison des Esclaves em Gorée (8'32'), obra realizada pelo artista brasileiro Ayrson Heráclito (Macaúbas, Bahia, 1968), a partir da versão exibida no Museu de Arte de São Paulo Assis Chateaubriand (MASP) em 2018. Como abordagem metodológica foi utilizada, para uma discussão sobre a obra, a perspectiva conceitual de lugares da memória (les lieux de mémóire) desenvolvido por Pierre Nora, em 1984. Para Nora, os lugares de memória são aqueles onde a memória se cristaliza e se refugia. Seriam uma espécie de substituto da memória, simbolicamente representam o que resta e o que se perpetua de um outro tempo até o presente.

Palavras chave Lugares da memória, Arte contemporânea, Videoinstalação, Arte afro-brasileira. 
da Interculturalidade

à Tecnologia

\section{Places of memory in the work of Ayrson Heráclito}

Abstract The purpose of this article is to reflect on the video installation Os Sacudimentos (2015), a video installation consisting of two videos called O Sacudimento da Casa da Torre (8'32 ') and O Sacudimento da Maison des Esclaves em Gorée (8'32'), a work by the Brazilian artist Ayrson Heráclito (Macaúbas, Bahia, 1968), based on the version shown at the São Paulo Art Museum Assis Chateaubriand (MASP) in 2018. As a methodological approach, for a discussion of the work, the conceptual perspective of places of memory (les lieux de mémóire) developed by Pierre Nora, in 1984. For Nora, places of memory are those where memory is crystallizes and takes refuge. They would be a kind of substitute the memory, which symbolically representing what remains and what is perpetuated from another time to the present.

Keywords Places of memory, Contemporary art, Video installation, Afro-Brazilian art.

\section{Lugares de memoria en la obra de Ayrson Heráclito}

Mirtes Marins de Oliveira é curadora pesquisadora e docente do PPG Design da Universidade Anhembi Morumbi. Pós-Doutorado em Educação - DE-USP. Possui graduação em Educação ArtísticaArtes Plásticas pela Universidade de São Paulo (1986), mestrado (1997) e doutorado (2002) em Educação: História, Política, Sociedade pela Pontifícia Universidade Católica de São Paulo.

<mirtescmoliveira@gmail.com > ORCID: 0000-0002-7132-0875
Resumen Este artículo tiene como objetivo reflexionar sobre la instalación de video Os Sacudimentos (2015), una instalación de video compuesta por dos videos llamados The Shaking of Casa da Torre (8'32 ') y The Shaking of Maison des Esclaves em Gorée (8'32') , una obra del artista brasileño Ayrson Heráclito (Macaúbas, Bahía, 1968), basada en la versión expuesta en el Museo de Arte Chateaubriand de São Paulo (MASP) en 2018. Como enfoque metodológico, para una discusión del trabajo, la perspectiva conceptual de los lugares de memoria (les lieux de mémóire) desarrollada por Pierre Nora, en 1984. Para Nora, los lugares de memoria son aquellos donde la memoria se cristaliza y se refugia. Serían una especie de sustituto de la memoria, representando simbólicamente lo que queda y lo que se perpetúa desde otro momento hasta el presente.

Palabras clave Lugares de memoria, Arte contemporáneo, Videoinstalación, Arte afrobrasileño. 


\section{Introdução}

Nos países da diáspora africana, a revisão das narrativas dos processos de escravidão ganha importância entre artistas afrodescendentes, como no caso do brasileiro Ayrson Heráclito. Na obra desse artista, questões ritualísticas e simbólicas pertencentes à religiosidade de matriz africana são recorrentes. No presente artigo pretende-se refletir, por meio do conceito de lugares da memória (Les Lieux de Mémóire) de Pierre Nora ${ }^{1}$, historiador francês conhecido pelos seus trabalhos sobre identidade francesa e memória, sobre a videoinstalação Os Sacudimentos de Ayrson Heráclito (2015/2018).

Portanto, o artigo será dividido em três partes. Em uma primeira será apresentado o conceito de lugares da memória de Pierre Nora. Numa segunda um descritivo da obra Os Sacudimentos, videoinstalação de Ayrson Heráclito, em sua versão exibida no Museu de Arte de São Paulo Assis Chateaubriand (MASP) em 2018. Numa terceira, à luz dos conceitos de Pierre Nora, será construída uma reflexão da obra de Ayrson Heráclito.

\section{Pierre Nora e os lugares da memória}

Pierre Nora é historiador francês, comumente associado à terceira geração da chamada Escola de Annales e da corrente historiográfica denominada Nova História (Nouvelle Histoire), indicação relacionada aos três volumes da obra Fazer a História organizada por Nora junto ao também historiador francês Jacques Le Goff.

Em seu texto "Entre memória e história - a problemática dos lugares", Pierre Nora diagnosticou uma aceleração da história que resulta numa valorização cada vez maior da memória e seus suportes, os lugares da memória (les lieux de mémóire).

De acordo com o autor, a aceleração do ritmo de transformações dos processos históricos, decorrente da mundialização, democratização, massificação e da midiatização da sociedade, causaram um desmoronamento da memória, o fim das sociedades-memória, aquelas que asseguravam a conservação e transmissão de valores e o fim das ideologias-memória, aquelas que garantiam a "passagem regular do passado para o futuro ou indicavam o que se deveria reter do passado para preparar o futuro" (NORA, 1993, p. 8). A dinâmica e rapidez dos fatos e a sensação de efemeridade produziriam um passado morto. Conforme esclarece Nora: 
uma oscilação cada vez mais rápida de um passado definitivamente morto, a percepção global de qualquer coisa como desaparecida - uma ruptura de equilíbrio. $\mathrm{O}$ arrancar do que ainda sobrou de vivido no calor da tradição, no mutismo do costume, na repetição do ancestral sob o impulso de um sentimento histórico profundo. A ascensão à consciência de si mesmo sob o signo do determinado, o fim de alguma coisa desde sempre começada. Fala-se tanto de memória porque ela não existe mais (NORA, 1993, p. 7).

Processo que evidencia as sociedades condenadas ao esquecimento na contemporaneidade. Sociedades dos vestígios e das trilhas, da história, que investem tanto poder na ideia do novo e no dever da constante mudança. Diferentemente das sociedades tradicionais, que vivem

uma memória integrada, ditatorial e inconsciente de si mesma, organizadora e toda-poderosa, espontaneamente atualizadora, uma memória sem passado que reconduz eternamente a herança, conduzindo o antigamente dos ancestrais ao tempo indiferenciado dos heróis, das origens e do mito (NORA, 1993, p. 8).

Longe de serem sinônimos, memória e história não se confundem. Opõem-se. Segundo o autor, "a memória aloja a lembrança no sagrado, a história liberta" (NORA, 1993, p.9). e torna a lembrança sempre prosaica

Memória é um processo vivido, conduzido por grupos vivos, portanto, em evolução permanente e suscetível a todas as manipulações, como os esquecimentos e projeções. Assim afirma Nora:

a memória é a vida, sempre carregada por grupos vivos e, nesse sentido, ela está em permanente evolução, aberta à dialética da lembrança e do esquecimento, inconsciente de suas deformações sucessivas, vulnerável a todos os usos e manipulações, susceptível de longas latências e de repentinas revitalizações. (...) é afetiva e mágica, a memória não se acomoda a detalhes que a confortam; ela se alimenta de lembranças vagas, telescópicas, globais ou flutuantes, particulares ou simbólicas, sensível a todas as transferências de cenas, censuras ou projeções (NORA, 1993, p. 9).

Citando Maurice Halbwachs, Nora afirma que existem "tantas memórias quantos grupos existem; que ela é, por natureza, múltipla e desacelerada, coletiva, plural e individualizada." (NORA, 1993, p.9). A memória está diretamente interligada a uma coletividade. 
Halbwachs afirma que a memória está diretamente relacionada a grupos de pertencimento, que possuem causas comuns. $\mathrm{O}$ ser humano se compreende como sujeito inserido no tecido social. A memória seria conexão, que emerge na relação com o outro, em especial com as comunidades afetivas.

Memória pressupõe vivência, ao contrário da história que é mediação, registro, é uma operação intelectual.

\footnotetext{
A história é a reconstrução sempre problemática e incompleta daquilo que não é mais. (...) uma representação do passado. (...) A história, porque operação intelectual e laicizante, demanda análise e discurso crítico. (...) A história, ao contrário, pertence a todos e a ninguém, o que lhe dá uma vocação para o universal (NORA, 1993, p. 9).
}

Quanto menos se vive a memória no interior, maior a necessidade de suportes exteriores. Assim nascem e vivem o que Pierre Nora chama de lugares da memória (les lieux de mémóire), lugares onde a memória pulsa e persiste, se encarna tornando-se realidade tangível e simbólica. "Só é lugar de memória se a imaginação o investe de uma aura simbólica. (...) Só entra na categoria se for objeto de um ritual" (NORA, 1993, p. 21).

Os lugares de memória seriam segundo o autor, lugares simultaneamente materiais, simbólicos e funcionais, divergindo somente em graus. Neles a separação entre história e memória não seria rígida, mas constituídos em "um jogo da memória e da história, uma interação dos dois fatores que leva à sua sobredeterminação recíproca" (NORA, 1993, p. 22). Podem ser localizações geográficas, edifícios ou construções, pequenos ou grandes objetos, mas também construções virtuais, pequenos gestos ou performatividades. "A memória se enraíza no concreto, no espaço, no gesto, na imagem, no objeto" (NORA, 1993, p. 9).

"Se habitássemos ainda nossa memória, não teríamos necessidade de lhe consagrar lugares" (NORA, 1993, p. 8). Os lugares da memória são um resto de memória. Um refúgio desta. Uma forma substituta, ou como o autor denomina uma memória-prótese.

Os lugares de memória surgem e vivem da constatação que não há mais memória espontânea. Por isso nos tornamos acumuladores de vestígios e produtores de arquivos como nunca antes observado na história da humanidade.

\section{Ayrson Heráclito a unir fronteiras e a sacudir a história}

Ayrson Heráclito (Macaúbas, Bahia, 1968) é um artista, curador, professor, mestre em artes visuais pela da Universidade Federal da Bahia (UFBA), Doutor em comunicação e semiótica pela Pontifícia Universidade Católica (PUC) de São Paulo. No final da década de 1980, inicia suas pesquisas na linguagem da performance ainda enquanto cursava educação artística pela 
Universidade Católica do Salvador (UCSAL). Na década seguinte, durante o desenvolvimento de sua pesquisa de mestrado e permanecia em Salvador, aprofundar suas reflexões sobre identidade baiana, realizando seus primeiros trabalhos com dendê̂, carne de charque e açúcar, materiais simbólicos que virão a se tornar recorrentes em suas obras até os dias atuais, devido ao interesse em suas práticas artísticas nas ligações históricas, políticas, sociais e culturais entre África e Brasil. Sua produção transita entre linguagens como a fotografia, instalação, performance e audiovisual. Tem participado de festivais e mostras em âmbito nacional e internacional como a $57^{\mathrm{a}}$ edição da Bienal de Veneza (2017); a Afro-Brazilian Contemporary Art, Europalia. Brasil, Bruxelas (2012); Trienal de Luanda (2010), entre outras.

Os Sacudimentos (2018) é uma videoinstalação composta por dois vídeos denominados 0 Sacudimento da Casa da Torre (8'32') (Figura 1) e 0 Sacudimento da Maison des Esclaves em Gorée (8'32') (Figura 2). Ambos projetados simultaneamente em paredes opostas e espelhados entre si, em uma sala escura, com paredes pintadas de preto, cuja única iluminação provinha das próprias projeções. Como narrativa do vídeo, o que se vê, inicialmente e em cada uma delas, é um close em uma grande árvore. Em cada uma das projeções, a espécie de árvore é diferente. Em seguida, em cada uma das projeções, surgem três homens, todos vestidos de branco, posicionados simetricamente diante de um edifício. Em postura hierática, seguram em cada uma das mãos, maços de folhas e ervas. Na sequência vemos os mesmos homens, empunhando os maços de folhas, entrando e passando-os por todas as paredes dos edifícios. Durante todo o processo podemos escutar o barulho do mar, mesclado com os ruídos do esfregar das folhas nas paredes. Ao final, as folhas são descartadas ao mar no vídeo da Maison des Esclaves, e na vegetação local no entorno da Casa da Torre.

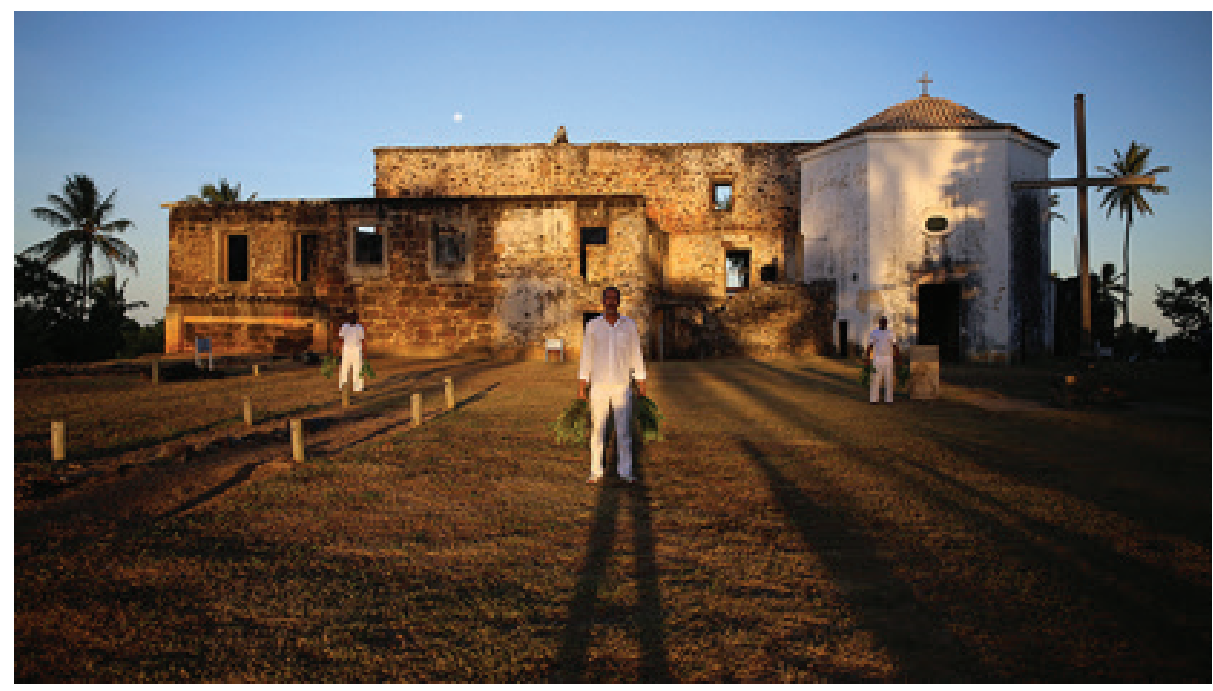

Fig 1. Frame de O Sacudimento da Casa da Torre

Fonte: http://www.premiopipa.com/pag/ayrson-heraclito/ 
A ação que o vemos realizar em ambos os vídeos - o passar maço de folhas nas paredes - é um ritual conhecido pelos participantes das religiões de matriz africana, como o Candomblé, religião a qual Heráclito pertence. O ritual, que também dá nome a obra, é, segundo aquela matriz, voltado para a limpeza e cura de ambientes domésticos. Segundo a religião, com um maço de folhas e ervas possuidoras de propriedades mágicas, é possível afastar e expulsar os eguns dos ambientes, almas desencarnadas, espíritos de mortos que vagam e lastimam a vida terrena, permanecendo entre os vivos e trazendo infortúnios a estes. Acredita-se que a energia contida nas folhas, seja muito quente, contraria a dos eguns, possibilitando varre-los para fora das casas.

Que edifícios seriam aqueles que Heráclito escolheu para varrer as energias ruins e expulsar os fantasmas? São, ambos, dois importantes sítios arquitetônicos históricos, ligados ao sistema colonial português e a escravização de povos africanos. Cada um dos vídeos mostra um deles.

O primeiro, a Casa da Torre, localizada no município de Mata de São João, Praia do Forte, no litoral norte na Bahia, possivelmente o maior equipamento administrativo do sistema colonial português construído fora da Europa. O edifício hoje em ruínas, pertenceu a Garcia d'Ávila (1528-1609),

ilustre fazendeiro baiano, riquíssimo, nobre pelos quatro costados e pelas conquistas e títulos honoríficos de seus antepassados, o autor de uma série de torturas e castigos contra seus escravos, que o torna merecedor do deplorável título de o maior carrasco de que até então se tem notícia na história do Brasil. Triste sina: o mais rico e o mais cruel de todos os brasileiros escravistas (MOTT, 2010, p. 67).

Na outra projeção, vemos a Maison des Esclaves, na Ilha de Gorée, no Senegal, um dos maiores centros de comércio de escravos do continente africano no passado. Nos porões deste edifício, construído por volta de 1780, famílias eram separadas e mantidas em celas de homens, mulheres e crianças, a espera dos navios que os transportaria para a América na condição de escravizados. Operava como limiar espacial e temporal. O limiar final da construção, tratava-se do que hoje é chamada de porta do não retorno. Ao passar por ela, os indivíduos, eram destituídos de sua humanidade, condenados ao exílio e ao trabalho sem fim que os levaria à morte.

Espelhadas na instalação, frente a frente, as projeções organizam o espaço da sala de projeções do MASP num espaço simbólico. O visitante é inserido corporalmente no centro de um microcosmo e do drama da diáspora africana.

Penetrar em uma videoinstalação é sempre um convite ao envolvimento sinestésico. Nela, todos os sentidos são acionados e sua experiência problematiza o olhar que é parte de um sujeito: não se aceita mais a posição clássica diante da obra, monocular, de um único ponto de vista central. 0 
espectador pode se movimentar livremente, podendo sair e voltar. Não se encontra unido e fixado à uma cadeira, como na experiência do cinema, no qual se vê vinculado a uma narrativa de forma passiva. A ele é dado um espaço para tomar decisões, encarar, desviar, recuar e avançar. Como testemunha, tem a possibilidade de rememorar a partir de lugares da memória. Lançando um olhar para o passado, reatualizando-o no presente.

\section{Rememorar e re/escrever ${ }^{2}$ a história}

Segundo Pierre Nora (1993), nunca se falou tanto em memória, exatamente porque ela não existe mais. Essa recorrência pode ser verificada, no discurso de muitos artistas na contemporaneidade, que têm em suas práticas, a necessidade de consagrar lugares à memória, seja pesquisando, buscando e revelando lugares nos quais a memória se encontra cristalizada ou mesmo criando dispositivos para encarná-la. A intenção com a ocupação desses lugares é de re/escrever narrativas sugerindo a revisão crítica de uma história única, universal e eurocêntrica, como é o caso de Ayrson Heráclito nesse trabalho.

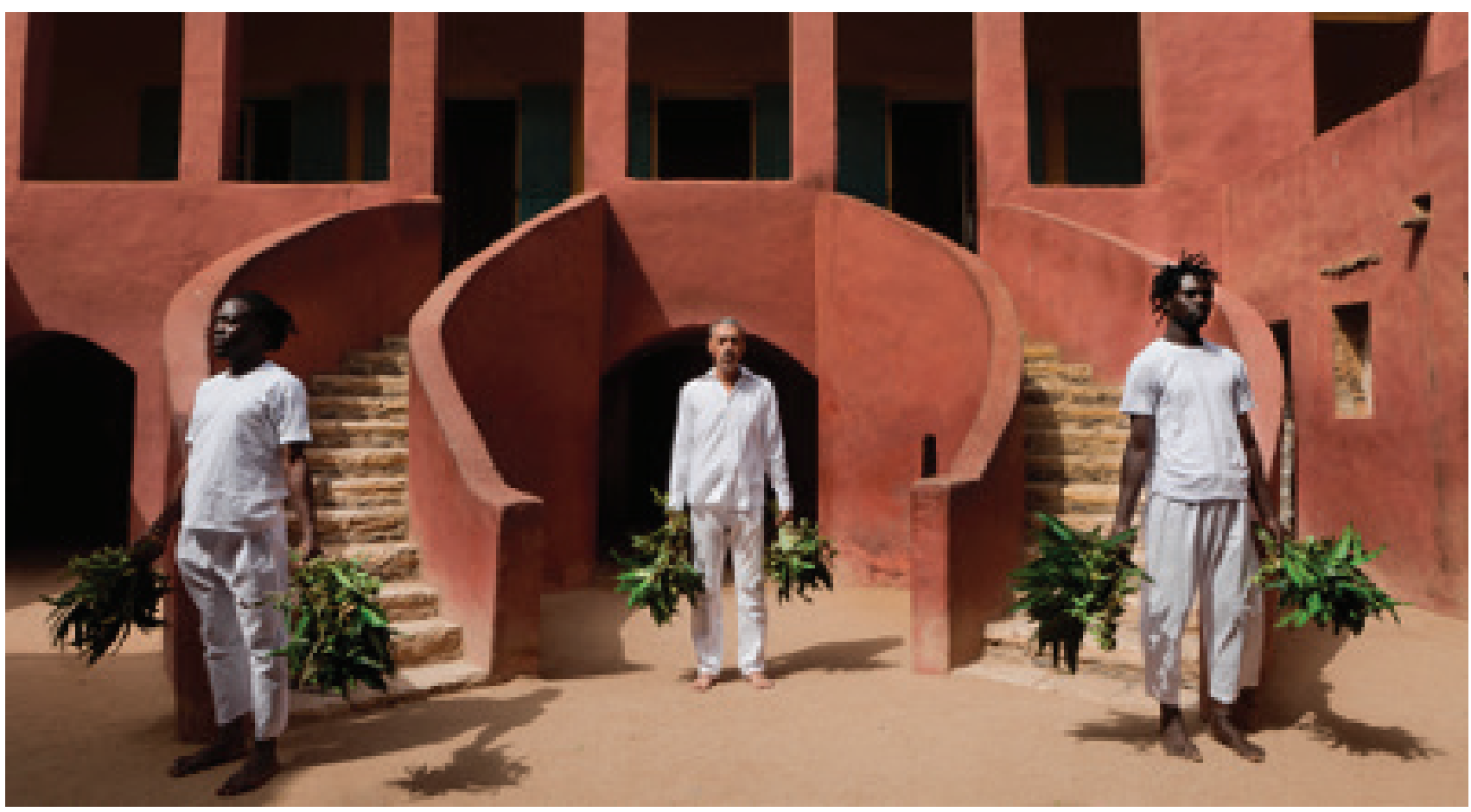

Fig 2. Frame de o Sacudimento da Maison des Esclaves em Gorée Fonte http://mafro.ceao.ufba.br/ptbr/exposicoes-temporaria/bori-exposicao-de-ayrso-heraclito
As escolhas de ambos sítios arquitetônicos, Casa da Torre de Garcia d'Ávila, na Bahia e Maison des Esclaves, na Ilha de Gorée, para o artista realizar suas ações, são carregadas de vontade de memória. São escolhas conscientes de lugares nos quais se encontram refugiadas memórias silenciadas pela história oficial branca e europeia. Não se pode esquecer como Nora já afirmou: "a memória é sempre suspeita para a história" (NORA, 1993, p.9). 
Nem só de locais geográficos se refere o conceito de lugares da memória de Pierre Nora. A memória não se enraíza só no concreto, na rocha ou em algo palpável. O gesto também pode ser reminiscência, investido de aura simbólica e ritual, exatamente como observamos nos vídeos a varredura com folhas do sacudimento. Toda performatividade observada em ambos os vídeos é sacralizada e fenômeno sempre atual. Gestualidade diretamente relacionada a um grupo de pertencimento, que compartilha causas comuns e concepções semelhantes do mundo, devido suas crenças religiosas.

A própria instalação torna-se um lugar da memória. Espaço concebido pelo artista que reorganiza espacialmente o ambiente de tal maneira ao instalar as projeções frente a frente, que inserindo o visitante no centro da ação, é como se este participasse de um ritual. Porém a dinâmica da experiência com a obra é em parte decidida pelo visitante.

\section{Considerações Finais}

Disputas narrativas por novas definições e organizações geopolíticas na arte, refletem grupos que não se identificam com as perspectivas vigentes. Buscam protagonismo e que suas vozes há muito silenciadas, sejam ouvidas.

A passagem da memória à história, como afirma Nora (1993), coloca os grupos para revitalizarem a sua própria história e identidade. 0 dever da memória faz de cada um historiador de si mesmo.

No Brasil, artistas afrodescendentes entre outros, atualmente, propõem mudança nessas perspectivas hegemônicas branco-europeias que ainda impregnam todas as esferas do tecido social, inclusive a produção e reprodução de subjetividades. A colonialidade ainda sobrevive, perpassando o colonialismo histórico.

A crise do modelo da história única, linear e universal decorre da erosão dos valores formativos do modernismo junto a aceleração dos processos históricos, resultante da mundialização nos dias atuais. O fim de uma tradição historiográfica baseado num modelo eurocêntrico gera a necessidade e urgência de outras e novas narrativas para além daquelas já estabilizadas.

Agradecimentos

$\mathrm{O}$ presente trabalho foi realizado com apoio da Coordenação de Aperfeiçoamento de Pessoal de Nível Superior - Brasil (CAPES) - Código de Financiamento 001. 
1 NORA, Pierre. Entre memória e história: a problemática dos lugares. In: Projeto História. São Paulo, n. 10, p. 7-28, dez. 1993

2 ARANTES, Priscila. Re/escrituras da Arte Contemporânea - História, Arquivo e Mídia. Sulinas. Porto Alegre. 2015

\section{Referências}

ANDRADE, Renan; ARANTES, Priscila. Associar, dissimular e zelar: Estratégias de (re)existência na formação da objetuária sacra afro-brasileira. In: DATJournal, v. 4, n. 2, p. 77-83. ago. 2019. Disponível em: https://doi.org/10.29147/dat.v4i2.132. Acesso em: 16/02/2020. ARANTES, Priscila. Re/escrituras da Arte Contemporânea - História, Arquivo e Mídia. Porto Alegre: Sulinas, 2015.

FORTES, Hugo. Dos objetos às coisas na poética da performance. In: DATJournal, v. 3, n. 1, p. 131-146. Jun. 2018. Disponível em: https://doi.org/10.29147/dat.v3i1.77. Acesso em: $16 / 02 / 2020$.

HERÁCLITO, Ayrson. Ayrson Heráclito > The Shakings: The meeting of the Atlantic Margins / O Sacudimento: a reunião das Margens Atlânticas. Disponível em: https:// inresidence.videobrasil.org.br/2015/08/24/os-sacudimentos-a-reuniao-das-margens-atlanticas-projeto-finalizado-durante-o-premio-de-residencia-sesc_videobrasil-na-raw-material-company-dacar-senegal/. Acesso em: 04/10/2019.

MOTT, Luiz. Bahia Inquisição \& Sociedade. Salvador: Editora da Universidade Federal da Bahia, 2010.

NORA, Pierre. Entre memória e história: a problemática dos lugares. In: Projeto História. Tradução de Yara Aun Khouri. São Paulo, n. 10, p. 7-28, dez. 1993. Disponível em: https:// revistas.pucsp.br/revph/article/view/12101/8763. Acesso em: 16/02/2020. 